\title{
Camel Milk Triggers Apoptotic Signaling Pathways in Human Hepatoma HepG2 and Breast Cancer MCF7 Cell Lines through Transcriptional Mechanism
}

\author{
Hesham M. Korashy, ${ }^{1}$ Zaid H. Maayah, ${ }^{1}$ Adel R. Abd-Allah, ${ }^{1}$ \\ Ayman O. S. El-Kadi, ${ }^{2}$ and Abdulqader A. Alhaider ${ }^{3}$ \\ ${ }^{1}$ Department of Pharmacology and Toxicology, College of Pharmacy, King Saud University, Riyadh 11451, Saudi Arabia \\ ${ }^{2}$ Faculty of Pharmacy and Pharmaceutical Sciences, University of Alberta, Edmonton, AB, Canada T6G 2E1 \\ ${ }^{3}$ Department of Pharmacology, College of Medicine, King Saud University, Riyadh 11461, Saudi Arabia
}

Correspondence should be addressed to Abdulqader A. Alhaider, aqahaider@hotmail.com

Received 24 November 2011; Accepted 27 January 2012

Academic Editor: Kazim Husain

Copyright ( $) 2012$ Hesham M. Korashy et al. This is an open access article distributed under the Creative Commons Attribution License, which permits unrestricted use, distribution, and reproduction in any medium, provided the original work is properly cited.

\begin{abstract}
Few published studies have reported the use of crude camel milk in the treatment of stomach infections, tuberculosis and cancer. Yet, little research was conducted on the effect of camel milk on the apoptosis and oxidative stress associated with human cancer. The present study investigated the effect and the underlying mechanisms of camel milk on the proliferation of human cancer cells using an in vitro model of human hepatoma (HepG2) and human breast (MCF7) cancer cells. Our results showed that camel milk, but not bovine milk, significantly inhibited HepG2 and MCF7 cells proliferation through the activation of caspase-3 mRNA and activity levels, and the induction of death receptors in both cell lines. In addition, Camel milk enhanced the expression of oxidative stress markers, heme oxygenase- 1 and reactive oxygen species production in both cells. Mechanistically, the increase in caspase-3 mRNA levels by camel milk was completely blocked by the transcriptional inhibitor, actinomycin D; implying that camel milk increased de novo RNA synthesis. Furthermore, Inhibition of the mitogen activated protein kinases differentially modulated the camel milk-induced caspase-3 mRNA levels. Taken together, camel milk inhibited HepG2 and MCF7 cells survival and proliferation through the activation of both the extrinsic and intrinsic apoptotic pathways.
\end{abstract}

\section{Introduction}

Apoptosis is a physiological cellular process of cell death that is initiated by a wide variety of extrinsic and intrinsic signals and stimuli and hence critical in several disease processes [1]. These signals instructing the cells to undergo apoptosis through the activation of a family of proteins known as caspases. The intrinsic signals can initiate apoptosis through mitochondrial oxidative stress caused by free radicals [2] This involves a balance between proapoptotic and antiapoptotic proteins, which enhance permeability of the mitochondrial outer membrane for the release of caspase activators [1]. On the other hand, the extrinsic signals induce apoptosis through binding of cell surface death receptors, such as tumor necrosis factor (TNF) receptor 1 (TNFR-1), TNFrelated apoptosis-inducing ligand receptor 1 (TRAILR-1, death receptor DR4, and DR5) [1,3]. Upon ligand binding activated DRs recruit adaptor proteins that bind to and activate initiator caspases, such as caspase- 8 or caspase-10, that in turn activate effector caspases such as caspase-3 [4]. Caspase- 3 has been identified as the major caspase that contributes to the hallmark of apoptosis, in which activated caspase- 3 causes the cell to undergo apoptosis through the cleavage of the key cellular proteins, such as cytoskeletal proteins, that leads to the typical morphological changes observed in cells undergoing apoptosis $[1,3]$.

Studies using transgenic and knockout mice provide direct evidence that disruption of apoptosis can promote tumor development and metastasis [3]. In addition, most of clinically used cytotoxic anticancer drugs, such as doxorubicin, 5-Furouracil (5-FU), and cis-platinum, are able to trigger apoptosis in susceptible tumor cells [5]. Thus, 
one of the strategies for inhibition of cancer development includes attenuation of pro- and/or anti-apoptotic genes. Therefore, the development of new chemopreventive agents that is able to inhibit cell proliferation and induce apoptosis in cancer cells but with less or no side effects is important and anticipated.

Chemoprevention by dietary constituents in the form of functional food has a well-established beneficial role in health promotion and emerged as a novel approach to control cancers [6]. Camel milk is an important nutritional source that consumed fresh or curdled and historically been used in the treatment of diverse diseases and for the maintenance of good health. The main components of the camel milk have been already determined [7], in that camel milk is different from other ruminant milk; having low cholesterol and sugar, high minerals and vitamins, and high concentrations of insulin [8]. Recent studies have reported that camel milk is the most effective milk among other species against Escherichia coli, Staphylococcus aureus, Salmonella typhimurium, and rotavirus $[9,10]$. In addition, it has been demonstrated that camel milk, in addition to secretory IgA and IgM, also contains numerous non-antibody components which possess antiviral activity, including lactoferrin [11]. Until recently, it is traditionally claimed that drinking camel milk has cured and treated numerous cases of cancer, however, this proclaimed health benefits of camel milk against cancer cells have never been exposed to scientific investigation.

A very few studies have been published in the literature regarding the medicinal properties of camel milk against cancer. A recent work from our laboratory have shown the ability of camel milk to significantly inhibit the induction of the cytochrome P4501A1 (Cyp1a1), a cancer-activating gene, and to induce the $\mathrm{NAD}(\mathrm{P}) \mathrm{H}$ : quinone oxidoreductase 1 (NQO1), cancer chemopreventive gene in murine hepatoma Hepa 1c1c7 cells at the transcriptional and posttranscriptional levels [8]. However, none of these few studies have investigated the effect of camel milk on the apoptosis and oxidative stress associated with human cancer cells. Therefore, the main objectives of the current study are to (a) determine the effect of camel milk on the proliferation of human hepatocellular carcinoma HepG2 and breast cancer MCF7 cells, (b) determine the effect of camel milk on apoptoticand oxidative stress-mediated genes in both cell lines, and (c) explore the molecular mechanisms involved.

\section{Materials and Methods}

2.1. Materials. Dulbecco's Modified Eagle's Medium (DMEM), protease inhibitor cocktail, 3-(4,5-dimethylthiazol-2-yl)-2,5-diphenyltetrazolium bromide (MTT), 4-(4-fluorophenyl)-2-(4-methylsulfinylphenyl)-5-(4-pyridyl)-1Himidazole (SB203580), 1,4-diamino-2,3-dicyano-1,4-bis(oaminophenylmercapto) butadiene ethanolate (U0126), actinomycin D (Act-D), 2,7-dichlorofluorescein diacetate (DCF-DA), and 1,9-pyrazoloanthrone (SP600125) were purchased from Sigma Chemical Co. (St. Louis, MO). $100 \times$ vitamin supplements were purchased from ICN Biomedicals Canada (Montreal, QC). TRIzol reagent was purchased from
Invitrogen Co. (Grand Island, NY). The High-Capacity cDNA reverse transcription kit and SYBR Green PCR Master Mix were purchased from Applied Biosystems (Foster City, CA, USA). Caspase-3 colorimetric activity kit was purchased from Biovision (Mountain View, CA, USA). Human forward and reverse primers were obtained from Integrated DNA Technologies (IDT, Coralville, IA). All other chemicals were purchased from Fisher Scientific Co. (Toronto, ON).

2.2. Collection of Camel and Bovine Milk. Camel and bovine milk samples were collected early morning daily from farm $200 \mathrm{~km}$ away from Riyadh city, Saud Arabia. The udders of each camel and bovine were washed and dried with a clean towel, and the teats were then swabbed with 70\% alcohol. The milk was collected from camels and bovines by hand milking as normally practiced by the farmers, and then collected and stored in sterile screw bottle. The milk was allowed to flow directly into stainless steel containers and then transferred to glass vials. The milk samples were transported to the laboratory as soon as practical $(<4 \mathrm{~h})$. The milks were then lyophilized and kept in the frozen state at $-80^{\circ} \mathrm{C}$ until use.

2.3. Cell Culture and Treatments. Human hepatoma HepG2 and breast cancer MCF7 cells (American Type Culture Collection, Manassas, VA) were maintained in DMEM, with phenol red supplemented with 10\% heat-inactivated fetal bovine serum, $20 \mu \mathrm{M}$ L-glutamine, $100 \mathrm{IU} / \mathrm{mL}$ penicillin $\mathrm{G}$, $10 \mu \mathrm{g} / \mathrm{mL}$ streptomycin, $0.1 \mathrm{mM}$ nonessential amino acids, and vitamin supplement solution. Cells were grown in $75 \mathrm{~cm}^{2}$ tissue culture flasks at $37^{\circ} \mathrm{C}$ under a $5 \% \mathrm{CO}_{2}$ humidified environment.

HepG2 and MCF7 cells were plated onto 12-well cell culture plates in DMEM culture media for caspase-3 activity and mRNA assays. Milk was prepared fresh just before each experiment and dissolved in dimethyl sulfoxide (DMSO). In all experiments, DMSO concentrations did not exceed $0.05 \%$ $(\mathrm{v} / \mathrm{v})$.

2.4. Cell Proliferation Assay. The capacity of camel milk to alter HepG2 and MCF7 cell proliferation and growth was determined by measuring the capacity of reducing enzymes present in viable cells to convert MTT salt to formazan crystals as described previously [12]. Twenty-four hours after incubating the cells with the tested camel and bovine milks in a 96-well cell culture plate at $37^{\circ} \mathrm{C}$ under a $4 \% \mathrm{CO}_{2}$ humidified incubator, the media were removed and a $100 \mu \mathrm{L}$ of serum-free medium containing $1.2 \mathrm{mM}$ of MTT dissolved in phosphate-buffered-saline (PBS), $\mathrm{pH} 7.4$, was added to each well. The plate was then incubated in a $\mathrm{CO}_{2}$ incubator at $37^{\circ} \mathrm{C}$ for $2 \mathrm{~h}$. The media were then decanted off by inverting the plate; and a $100 \mu \mathrm{L}$ of isopropyl alcohol was added to each well, with shaking for $1 \mathrm{~h}$ to dissolve the formazan crystals. The color intensity in each well was measured at wavelength of 550 using BIO-TEK Instruments EL 312e microplate reader, Bio-Tek Instruments (Winooski, VT). The percentage of cell viability was calculated relative to control wells designated as $100 \%$ viable cells using the following formula: $\left(A_{\text {treated }}\right) /\left(A_{\text {control }}\right) \times 100 \%$. 
TABle 1: Primers sequences used for real-time PCR reactions.

\begin{tabular}{lcc}
\hline Gene & Forward primer & Reverse primer \\
\hline CASPASE-3 & GAGTGCTCGCAGCTCATACCT & CCTCACGGCCTGGGATTT \\
p53 & GCCCCCAGGGAGCACTA & GGGAGAGGAGCTGGTGTTG \\
BCl 2 & CATGTGTGTGGAGAGCGTCAA & GCCGGTTCAGGTACTCAGTCA \\
DR 4 AGTACATCTAGGTGCGTTCCTG & GTGCTGTCCCATGGAGGTA \\
HO- 1 & ATGGCCTCCCTGTACCACATC & TGTTGCGCTCAATCTCCTCCT \\
NQO 1 & CGCAGACCTTGTGATATTCCAG & CGTTTCTTCCATCCTTCCAGG \\
$\beta$-actin & TATTGGCAACGAGCGGTTCC & GGCATAGAGGTCTTTACGGATGTC \\
\hline
\end{tabular}

2.5. Determination of Reactive Oxygen Species (ROS) Production. Intracellular ROS was analyzed fluorometrically by measuring the oxidation of a non-fluorescent probe 2,7dichlorofluorescein diacetate (DCF-DA) to a fluorescent metabolite dichlorofluorescein (DCF) by the mitochondrial ROS as described previously with slight modifications [13]. Briefly, HepG2 cells grown to $90 \%$ confluence in 96-well cell culture plates were treated for $24 \mathrm{~h}$ with various concentrations of camel milk. Thereafter, cells were washed with PBS before incubated for $30 \mathrm{~min}$ in fresh media containing $10 \mu \mathrm{M}$ DCF-DA. The fluorescence was directly measured using excitation and emission wavelengths of 485 and $535 \mathrm{~nm}$, respectively, using POLARstar Omega, BMG LabTech (Offenburg, Germany).

2.6. RNA Extraction and cDNA Synthesis. Total RNA was isolated using TRIzol reagent (Invitrogen) according to the manufacturer's instructions and quantified by measuring the absorbance at $260 \mathrm{~nm}$. RNA quality was determined by measuring the 260/280 ratio. Thereafter, first strand cDNA was synthesized using the High-Capacity cDNA reverse transcription kit (Applied Biosystems) according to the manufacturer's instructions. Briefly, $1 \mu \mathrm{g}$ of total RNA from each sample was added to a mix of $2.0 \mu \mathrm{L}$ of $10 \mathrm{x}$ reverse transcriptase buffer, $0.8 \mu \mathrm{L}$ of $25 \mathrm{x}$ dNTP mix $(100 \mathrm{mM})$, $2.0 \mu \mathrm{L}$ of $10 \mathrm{x}$ reverse transcriptase random primers, $1.0 \mu \mathrm{L}$ of MultiScribe reverse transcriptase, and $3.2 \mu \mathrm{L}$ of nuclease-free water. The final reaction mix was kept at $25^{\circ} \mathrm{C}$ for $10 \mathrm{~min}$, heated to $37^{\circ} \mathrm{C}$ for $120 \mathrm{~min}$, heated for $85^{\circ} \mathrm{C}$ for $5 \mathrm{~s}$, and finally cooled to $4^{\circ} \mathrm{C}[14]$.

2.7. Quantification of mRNA Expression by Real-Time Polymerase Chain Reaction (RT-PCR). Quantitative analysis of specific mRNA expression was performed by RT-PCR by subjecting the resulting $\mathrm{CDNA}$ to PCR amplification using 96-well optical reaction plates in the ABI Prism 7500 System (Applied Biosystems). The $25-\mu \mathrm{L}$ reaction mix contained $0.1 \mu \mathrm{L}$ of $10 \mu \mathrm{M}$ forward primer and $0.1 \mu \mathrm{L}$ of $10 \mu \mathrm{M}$ reverse primer ( $40 \mathrm{nM}$ final concentration of each primer), $12.5 \mu \mathrm{L}$ of SYBR Green Universal Master Mix, $11.05 \mu \mathrm{L}$ of nucleasefree water, and $1.25 \mu \mathrm{L}$ of cDNA sample. The primers used in the current study (Table 1) were purchased from Integrated DNA Technologies (IDT, Coralville, IA). Assay controls were incorporated onto the same plate, namely, notemplate controls to test for the contamination of any assay reagents. The RT-PCR data was analyzed using the relative gene expression (i.e., $\Delta \Delta \mathrm{CT}$ ) method as described previously [15]. Briefly, the data are presented as the fold change in gene expression normalized to the endogenous housekeeping gene $(\beta$-actin) and was determined using the equation fold change $=2^{-\Delta(\Delta \mathrm{Ct})}$, where $\Delta \mathrm{Ct}=\mathrm{Ct}_{(\text {target })}-\mathrm{Ct}_{(\beta \text {-actin })}$ and $\Delta(\Delta \mathrm{Ct})=\Delta \mathrm{Ct}_{\text {(treated })}-\Delta \mathrm{Ct}_{(\text {untreated })}$.

2.8. Determination of Caspase-3 Activity. Caspase-3 activity was measured colorimetrically using the CaspACE assay system purchased from Biovision (Mountain View, California, USA) according to the manufacturer's instructions. Briefly, HepG2 cells plated onto 12-well cell culture plate were treated for $24 \mathrm{~h}$ with different concentrations of camel milk. Thereafter, HepG2 ell were then collected by trypsinization and cell pellets were resuspended in ice-cold cell lysis buffer and incubated for $10 \mathrm{~min}$ on ice. The supernatant obtained by centrifugation for $10 \mathrm{~min}$ at $10,000 \times \mathrm{g}$ at $4^{\circ} \mathrm{C}$ was transferred to a fresh tube and stored at $-20^{\circ} \mathrm{C}$ until use. For measuring caspase- 3 activity, approximately $30 \mu \mathrm{g}$ protein was incubated with $200 \mu \mathrm{M}$ enzyme-specific colorimetric caspase- 3 substrate I, acetyl-Asp-Glu-Val-Asp p-nitroanilide (Ac-DEVD-pNA) at $37^{\circ} \mathrm{C}$ for $2 \mathrm{hr}$. Caspase- 3 activity was assessed by measuring absorbance at a wavelength of $405 \mathrm{~nm}$ with a plate reader (Bio-Tek Instruments, Winooski, VT).

2.9. Statistical Analysis. All results are presented as mean \pm SEM. The comparative analysis of the results from various experimental groups with their corresponding controls was performed using SigmaStat for Windows, Systat Software Inc., (San Jose, CA). One-way analysis of variance (ANOVA) followed by Student-Newman-Keul's test was carried out to assess which treatment groups showed a significant difference from the control group. The differences were considered significant when $P<0.05$.

\section{Results}

3.1. Effect of Camel Milk on HepG2 Cell Proliferation. To determine the capacity of camel milk to inhibit cancer cell growth and proliferation, HepG2 cells were treated for $24 \mathrm{~h}$ with increasing concentrations of camel or bovine milk ( 0 , $2.5,5,10,20,40$, and $80 \mathrm{mg} / \mathrm{mL}$ ), thereafter cell viability and proliferation were determined by MTT assay. Figure 1 shows that survival of HepG2 cells was significantly reduced following incubation with camel milk in a concentrationdependent manner, as compared to bovine milk which did not alter cell growth at all concentrations tested (Figure 1), suggesting that camel milk has tumor cell selectivity. The calculated $\mathrm{IC}_{50}$ for camel milk is approximately $76 \mathrm{mg} / \mathrm{mL}$. 


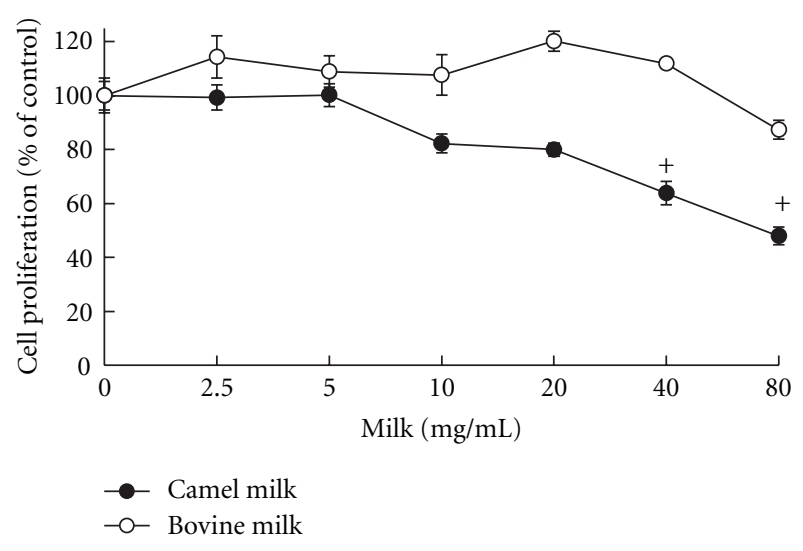

FIGURE 1: Effect of camel and bovine milks on HepG2 cell proliferation. Cells were incubated with various concentrations of camel and bovine milk for $24 \mathrm{~h}$, thereafter cell proliferation was assessed using the MTT assay. Values are presented as percentage of the control (mean \pm SEM, $n=8) .{ }^{+} P<0.05$ compared to control $(0 \mathrm{mg} / \mathrm{mL})$.

Based on these results, the camel milk concentrations of $2.5,5,10$, and $20 \mathrm{mg} / \mathrm{mL}$ were chosen to be utilized in all subsequent experiments.

3.2. Effect of Camel Milk on the mRNA Expression Level of Apoptotic Genes in HepG2 Cells. To examine whether the inhibitory effect of camel milk on HepG2 cells proliferation and growth is an apoptotic-mediated mechanism, we determined the capacity of camel milk to modulate the expression of apoptotic and antiapoptotic genes. For this purpose, HepG2 cells were incubated for $6 \mathrm{~h}$ with increasing concentrations of camel milk $(2.5,5,10$, and $20 \mathrm{mg} / \mathrm{mL})$, as determined by the MTT assay (Figure 1), thereafter Caspase-3, p53, Bcl2, and DR4 mRNA expression levels were determined by RT-PCR. Figure 2 shows that camel milk significantly induced caspase-3 and DR4 mRNA expression levels in a concentration-dependent manner (Figures 2(a) and $2(\mathrm{~d}))$. The maximum induction was observed at the highest concentrations tested $(20 \mathrm{mg} / \mathrm{mL})$ by approximately 7 and 10 folds, respectively. On the other hand, no significant changes in p53 and Bcl2 mRNA levels in response to camel milk were observed (Figures 2(b) and 2(c)).

3.3. Effect of Camel Milk on the Expression of Oxidative Stress Genes in HepG2 Cells. To further explore whether camel milk-induced apoptotic genes is associated with induction of oxidative stress markers in HepG2 cells, we examined the effect of camel milk on heme oxygenase 1 (HO-1) and NQO1 mRNAs and ROS production as oxidative stress marker. For this purpose, HepG2 cells were incubated for indicated time points with increasing concentrations of camel milk, thereafter HO-1 and NQO1 mRNA and ROS production were measured by RT-PCR and DCF assay, respectively. Figure 3(a) shows that camel milk significantly induced HO1 mRNA levels only at the higher concentrations tested, 10 and $20 \mathrm{mg} / \mathrm{mL}$, by approximately 3 and 4 folds, respectively. In addition, while camel milk did not alter the expression of NQO1 mRNA levels (Figure 3(b)), it significantly increased the ROS production at all concentrations tested in a concentration-dependent manner (Figure 3(c)) with a maximum induction of 10 -fold achieved by $20 \mathrm{mg} / \mathrm{mL}$ camel milk treatment.

3.4. Effect of Camel Milk on the Apoptotic and Oxidative Stress Genes in MCF7 Cells. To examine whether camel milkmediated apoptosis and oxidative stress is cancer-specific or could be extrapolated to other cancer types. For this purpose we determined the ability of camel milk to modulate the expression of apoptotic and oxidative stress genes in human breast cancer cells, MCF7 cells. Therefore, MCF7 cells were incubated with same concentration of camel milk for $6 \mathrm{~h}$, thereafter Caspase-3, DR4, and HO-1 mRNA levels (the markers that showed significant alterations in HepG2 cells) were determined by RT-PCR. Our results showed that camel milk, in a manner similar to what was observed with HepG2 cells (Figure 4), significantly induced Caspase-3 and DR4 mRNA expression levels in MCF7 cells in a concentration-dependent manner (Figures 4(a) and 4(b)), however; induced HO-1 mRNA levels only at the highest concentration tested $(20 \mathrm{mg} / \mathrm{mL})$ see Figure $4(\mathrm{c})$.

3.5. Effect of Camel Milk on Caspase-3 Activity in HepG2 Cells. In order to examine whether the induction of caspase- 3 mRNA by camel milk in HepG2 cells is translated into a functional catalytic activity, we examined the effect of camel milk on caspase-3 activity. For this purpose, HepG2 cells were treated for $24 \mathrm{~h}$ with increasing concentrations of camel milk; thereafter, caspse-3 activity was determined colormetrically using biovision kit as described in Section 2 Figure 5 shows that camel milk increased the caspase- 3 activity only at the higher concentrations, 10 and $20 \mathrm{mg} / \mathrm{mL}$ by approximately 2.5 and 6.5 folds, respectively.

3.6. Effect of the Transcription Inhibitor, Act-D, on the Induction of Caspase-3 mRNA by Camel Milk in HepG2 Cells. To further investigate whether the increase in caspase- $3 \mathrm{mRNA}$ by camel milk in HepG2 cells is attributed to an increase in the de novo RNA synthesis, HepG2 cells were treated for $6 \mathrm{~h}$ with camel milk $(20 \mathrm{mg} / \mathrm{mL})$ in the presence or absence of $5 \mu \mathrm{g} / \mathrm{mL}$ Act-D, an RNA synthesis inhibitor. Caspase-3 mRNA was then quantified by RT-PCR. If camel milk increased the amount of caspase-3 mRNA through increasing its de novo RNA synthesis under these circumstances, we would expect to observe a decrease in the content of Caspase-3 mRNA after the inhibition of its RNA synthesis.

Figure 6 shows that pretreatment of the cells with ActD did not significantly alter the constitutive expression of Caspase-3 mRNA as compared to untreated cells. However, the induction of Caspase- 3 mRNA by camel milk was completely abolished by Act-D, suggesting that camel milk increases the Caspase- 3 mRNA level by increasing its de novo RNA synthesis.

3.7. Effect of the Mitogen Activated Protein Kinases (MAPKs) Inhibitors on the Induction of Caspase-3 mRNA by Camel Milk in HepG2 Cells. To further investigate whether activation of the MAPK pathways is required for apoptotic cell death by 


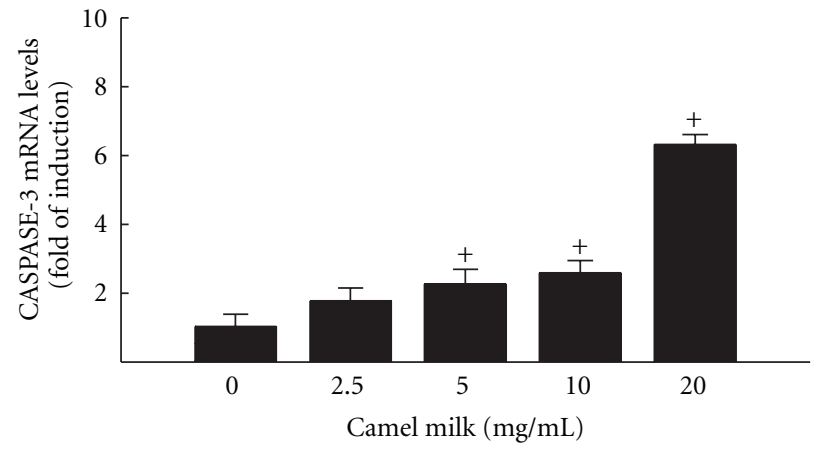

(a)

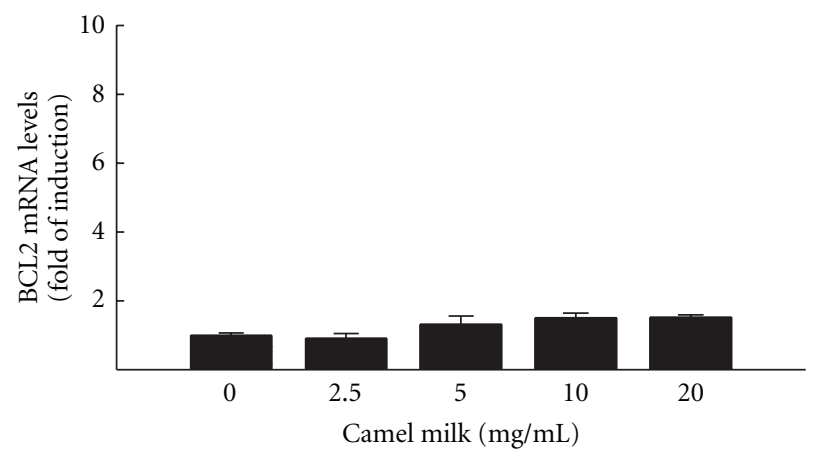

(c)

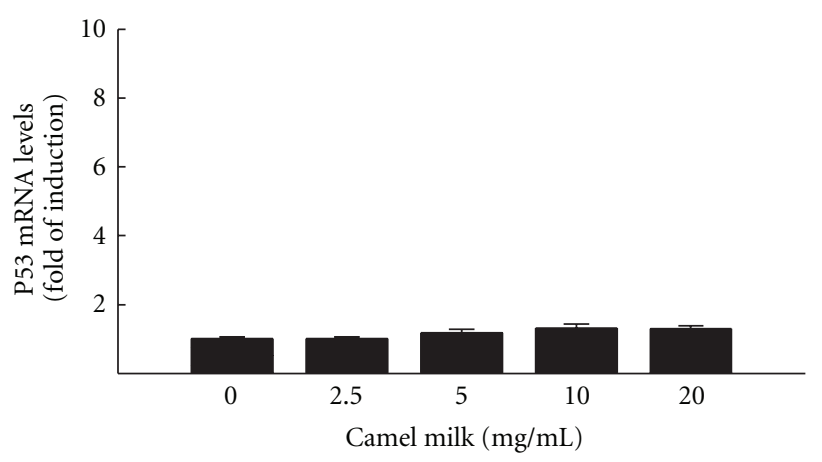

(b)

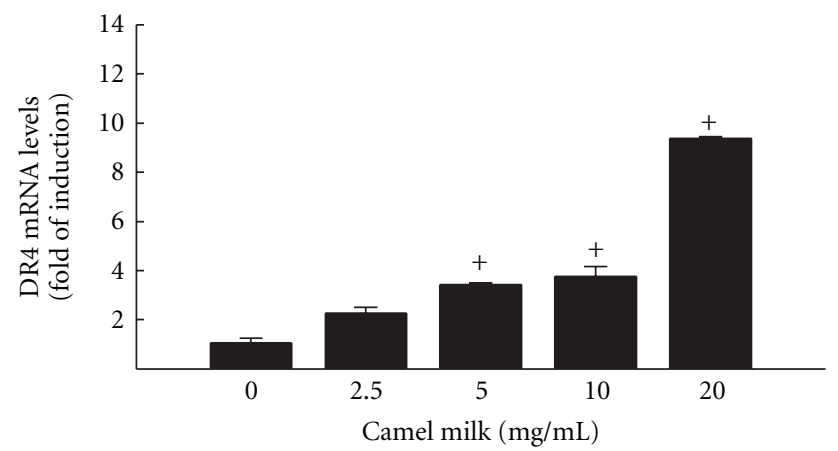

(d)

FIGURE 2: Effect of camel milk on apoptotic markers Caspase-3 (a), p53 (b), BcL2 (c), and DR4 (d) mRNA levels in HepG2 cells. HepG2 cells were treated for $6 \mathrm{~h}$ with a various concentrations of camel milk $(2.5,5,10$, and $20 \mathrm{mg} / \mathrm{mL})$. Thereafter, total RNA was isolated using TRIzol reagent, and the mRNA levels of Caspase-3, p53, BcL2, and DR4 were quantified using RT-PCR normalized to $\beta$-actin housekeeping gene as described in Section 2. Duplicate reactions were performed for each experiment, and the values presented are the means \pm SEM $(n=6)$ of three independent experiments. ${ }^{+} P<0.05$ compared to control $(0 \mathrm{mg} / \mathrm{ml})$.

camel milk, HepG2 cells were pretreated for $2 \mathrm{~h}$ with c-Jun $\mathrm{N}$ terminal kinases (JNK) inhibitor, SP600125 $(10 \mu \mathrm{M})$, Extracellular signal-regulated kinases (ERK) inhibitor, U0126 $(10 \mu \mathrm{M})$, and p38 MAPK inhibitor, SP203580 $(10 \mu \mathrm{M})[16]$ prior to the addition of camel milk $(10 \mathrm{mg} / \mathrm{mL})$ for additional $6 \mathrm{~h}$, thereafter capspase- 3 mRNA was quantified by RT-PCR. The effective concentrations of these inhibitors were selected by dose-response assays in order to prevent cytotoxicity (data not shown).

If camel milk-induced caspase-3 mRNA is mediated through MAPKs signaling pathways, inhibition of MAPK would prevent camel milk-mediated effects on caspase-3 gene expression. Figure 7 shows that pretreatment of the cells with MAPK inhibitors alone slightly but not significantly decreases the basal expression level of caspase-3 mRNA (Figure 7). Importantly, the induction of capsase-3 mRNA by camel milk in HepG2 cells was significantly decreased by both the JNK and p38 MAPKs inhibitors, SP600125 and SB203580, by approximately $100 \%$ and $80 \%$, respectively, whereas further potentiated by U0126, ERK inhibitor (Figure 7).

\section{Discussion}

The current study provides, to our knowledge, the first mechanistic evidence for the ability of camel milk to signif- icantly inhibit the growth and proliferation of human liver HepG2 and breast MCF7 cancer cells through apoptoticand oxidative stress-mediated mechanisms. In this study, molecular mechanisms underlying camel milk-induced cell growth inhibition and apoptosis were measured on the following perspectives: (a) the activation of caspase- 3 at the mRNA and activity levels, (b) the activation of DR4, (c) the accumulation of intracellular ROS, and (d) the role of MAPK signaling pathways.

Apoptosis is a tightly regulated process under the control of several signaling pathways, such as caspases and mitochondrial pathways $[4,17]$. Particularly, caspase- 3 is an important proapoptotic protein within the extrinsic and intrinsic apoptotic pathways [3]. Activation of caspase-3 plays a central role in the initiation of apoptosis, which requires the activation of initiator caspases, such as caspase8 or -9 , in response to proapoptotic signals [3]. Induction of apoptosis with generation of ROS by cancer chemoprotective agents, such as doxorubicin [2], not only induces cancer cell death but also causes DNA damage and genomic instability [18]. However, most of these cancer chemoprotective therapies are cytotoxic and their use is associated with toxicities. Thus, the development of new chemopreventive agents able to inhibit cell proliferation and induce apoptosis in cancer cells but with less or no side effects is important and anticipated. 


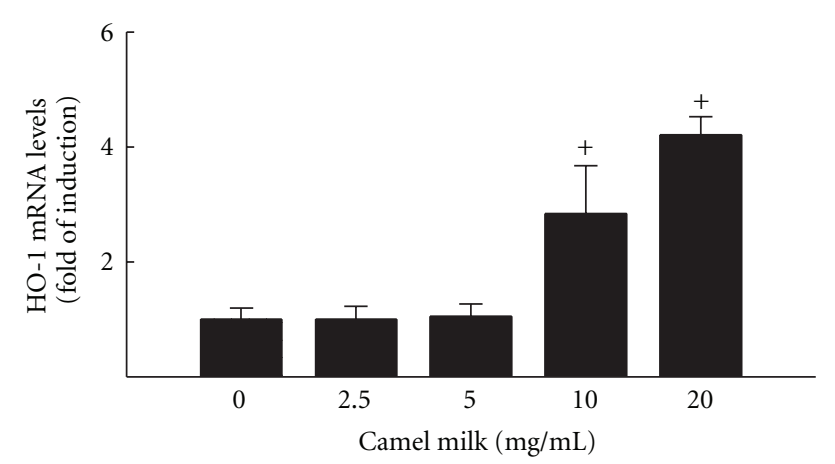

(a)

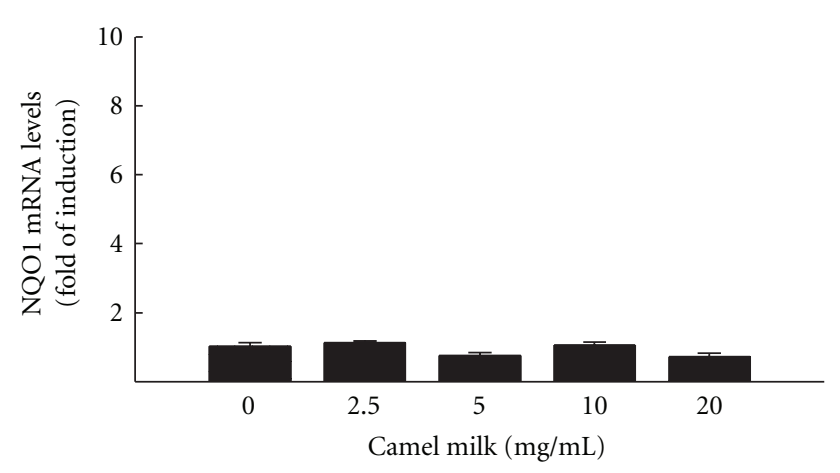

(b)

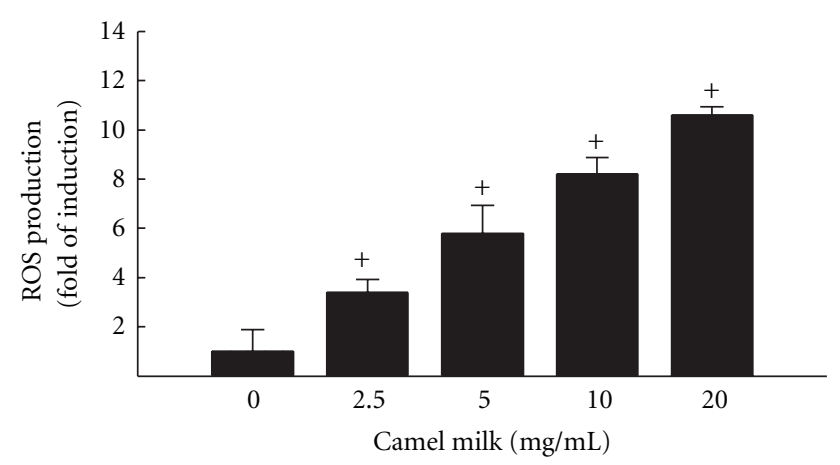

(c)

FIGURE 3: Effect of camel milk on oxidative stress markers HO1 (a) and NQO1 (b) mRNA levels, and ROS (c) production in HepG2 cells. (a) and (b) HepG2 cells were treated for $6 \mathrm{~h}$ with a various concentrations of camel milk $(2.5,5,10$, and $20 \mathrm{mg} / \mathrm{mL})$. Thereafter, total RNA was isolated using TRIzol reagent and the mRNA levels of HO-1 and NQO1 were quantified using RT-PCR normalized to $\beta$-actin housekeeping gene as described Section 2. Duplicate reactions were performed for each experiment, and the values presented are the means $\pm \operatorname{SEM}(n=6)$ of three independent experiments. ${ }^{+} P<0.05$ compared with untreated cells. (c) HepG2 cells were treated for $24 \mathrm{~h}$ with a various concentrations of camel milk $(2.5,5,10$, and $20 \mathrm{mg} / \mathrm{mL})$. Thereafter, cells were incubated with DCF-DA $(10 \mu \mathrm{M})$ for $1 \mathrm{~h}$. DCF formation was measured fluorometrically using excitation/emission wavelengths of $484 / 535 \mathrm{~nm}$. Values are presented as means \pm SEM, $n=8 .{ }^{+} P<0.05$, compared to control $(0 \mathrm{mg} / \mathrm{mL})$.

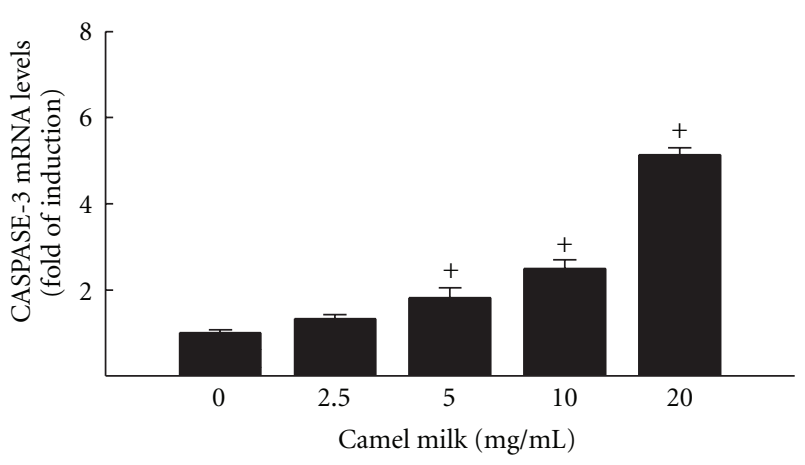

(a)

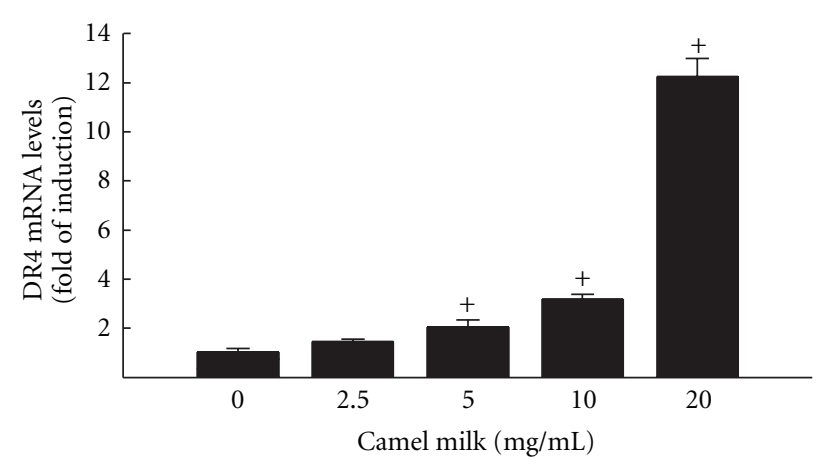

(b)

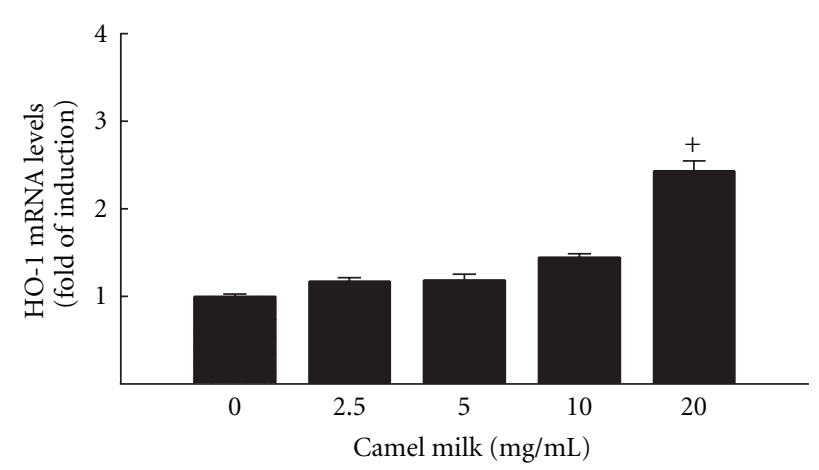

(c)

FIGURE 4: Effect of camel milk on apoptotic and oxidative stress markers Caspase-3 (a), DR4 (b), and HO-1 (c) mRNA levels in MCF7 cells. MCF7 cells were treated for $6 \mathrm{~h}$ with a various concentrations of camel milk $(2.5,5,10$, and $20 \mathrm{mg} / \mathrm{mL})$. Thereafter, total RNA was isolated using TRIzol reagent and the mRNA levels of Caspase-3, DR4, and HO-1 were quantified using RT-PCR normalized to $\beta$-actin housekeeping gene as described Section 2. Duplicate reactions were performed for each experiment, and the values presented are the means $\pm \operatorname{SEM}(n=6)$ of three independent experiments. ${ }^{+} P<0.05$ compared to control $(0 \mathrm{mg} / \mathrm{mL})$.

Previous study from our laboratory have reported the ability of camel milk to inhibit the expression of CYP1A1, a cancer-activating gene, and to induce the expression of NQO1, a chemoprotective gene, in murine hepatoma Hepa 1c1c7 cells [8]. However, the chemoprotective effect of camel milk against human cancer cells had not been examined 


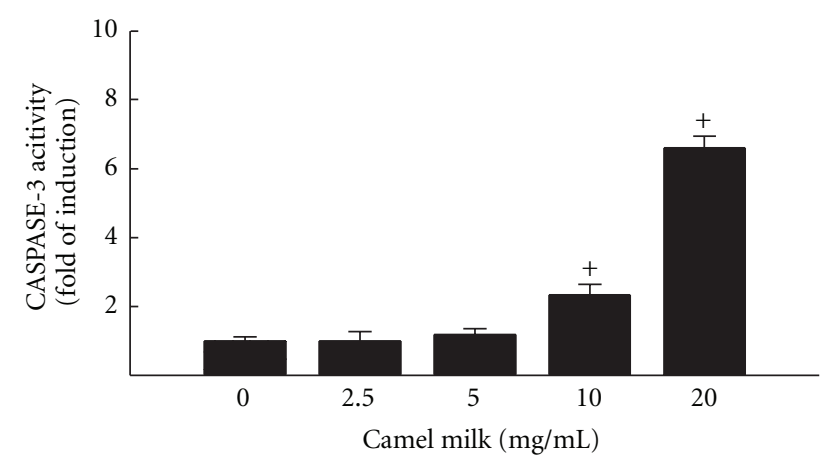

FIGURE 5: Effect of camel milk on apoptotic Caspase-3 catalytic activity in HepG2 cells. HepG2 cells were treated for $24 \mathrm{~h}$ with a various concentrations of camel milk $(2.5,5,10$, and $20 \mathrm{mg} / \mathrm{mL})$. Thereafter, caspase- 3 activity was determined calorimetrically using sing the CaspACE assay system purchased from Biovision. Caspase3 activity was assessed by measuring absorbance at a wavelength of $405 \mathrm{~nm}$ with a plate reader (Bio-Tek Instruments, Winooski, VT). Values are presented as mean $\pm \operatorname{SEM}(n=6) .{ }^{+} P<0.05$ compared to control $(0 \mathrm{mg} / \mathrm{mL})$.

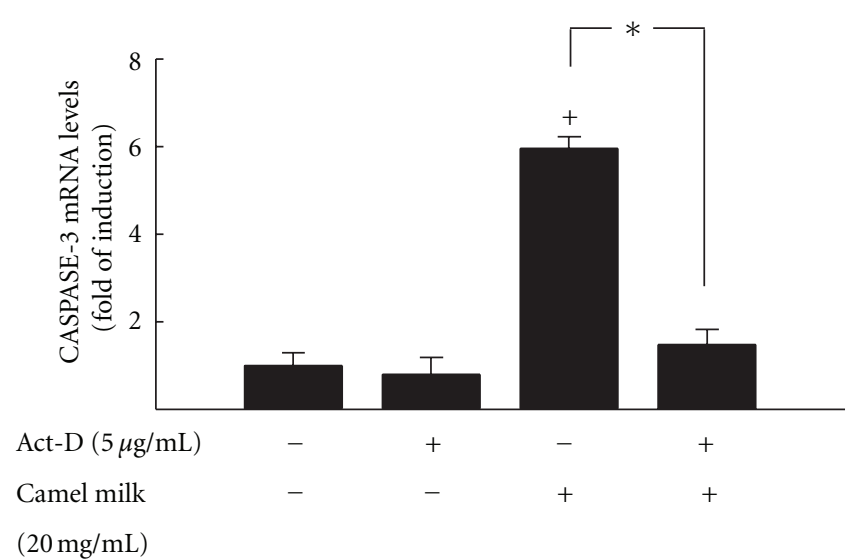

FIGURE 6: Effect of RNA synthesis inhibitor Act-D on the induction Caspase- 3 activity by camel milk in HepG2 cells. HepG2 cells were treated with $5 \mu \mathrm{g} / \mathrm{mL}$ Act-D, a RNA synthesis inhibitor, $30 \mathrm{~min}$ before exposure to camel milk $(20 \mathrm{mg} / \mathrm{mL})$ for additional $6 \mathrm{~h}$. The amount of Caspase-3 mRNA was quantified using RT-PCR and normalized to $\beta$-actin housekeeping gene. Duplicate reactions were performed for each experiment, and the values presented are the means \pm SEM $(n=6)$ of three inv experiments. ${ }^{+} P<0.05$ compared with control; ${ }^{*} P<0.05$ compared to same treatment in the absence of Act-D.

before. Therefore, to model the in vivo situation, human hepatoma HepG2 and breast cancer MCF7 cell lines were used in the current study to predict human responses to camel milk by investigating the capacity of camel milk to inhibit HepG2 and MCF7 cells growth and proliferation and explore the role of apoptosis in camel milk-mediated effect.

Initially, we have assessed the potential effect of camel milk to suppress the growth and proliferation of HepG2 cells using the MTT assay since this assay has been demonstrated to correlate with clinical outcome [19]. We demonstrated here that camel milk, but not bovine, was able to significantly suppress HepG2 cell proliferation and growth (Figure 1). Importantly, the camel milk-mediated effect in HepG2 cells is attributed to induction of apoptotic signaling pathway, as evidenced by activation of caspase- 3 mRNA and activity levels without changes in the expression of p53 and Bcl2 (Figure 2), suggesting a p53-independet mechanism. Although $p 53$ gene was the first tumor suppressor gene linked to apoptosis, DNA-induced apoptosis was shown in cell lines lacking p53 expression or mutated p53 [20]. Furthermore, studies using transgenic and knockout mice have reported the ability of several chemotherapeutic agents, such as curcumin [21] and doxorubicin [2], to induce apoptosis through a p53-independent pathway.

Cell surface death receptors have been identified as major pathway in apoptotic induction $[22,23]$, which involves the ligation of the TNF/Fas-receptor with its ligand followed by caspases activation [24]. Therefore, we have tested whether DRs are involved in camel milk-mediated effects by measuring the expression of DR4. In this regard, we have shown here that induction of DR4 mRNA in response to camel milk significantly contributes to the activation of caspase-3. Our results are in agreement with previous observations demonstrated that antitumor agents, such as ET, doxorubicin, AraC, 5-FU, and cis-platinum, or irradiation can upregulate the expressions of DR4 and DR5 in acute leukemia, multiple myeloma, and solid tumor cell lines [23, 25].

Activation of caspase- 3 has also been shown to be mediated through mitochondrial ROS production [26]. Our data provide evidence that the apoptotic cell death induced by camel milk in HepG2 cells is associated with ROS generation. This is in agreement with previous findings that ROS per se are potent inducers of apoptosis [27]. Taken together, it would suggest that induction of ROS in response to camel milk triggers caspase- 3 activation which is a direct effect and is not caused by a decrease in the levels of $\mathrm{Bcl}-2$, a protein possesses antioxidant function and blocks ROS production [28], as no changes in its mRNA expression was observed (Figure 2). Importantly, similar pattern of caspase-3, DR4, and HO-1 mRNAs induction was observed in human breast cancer MCF7 cells (Figure 4), suggesting that camel milkmediated effect is not specific to HepG2 cells. Taken together, these results indicate that HepG2 and MCF7 cells are susceptible to caspase-3-induced cell death, as overexpression of caspase- 3 induced direct cytotoxicity to the cells.

Mechanistically, we have shown here that the ability of camel milk to induce caspase-3 gene is a transcriptional mechanism. This was supported by the ability of the transcription inhibitor, Act-D, to significantly block the newly synthesized caspase-3, but not existing, mRNAs (Figure 6), suggesting a requirement of de novo RNA synthesis for the induction of caspase-3 mRNA by camel milk [29]. On the other hand, MAPK cascades play important roles in cell death and survival signaling $[30,31]$. Thus, we have examined and compared their role in casepase- 3 mRNA expression by camel milk using specific inhibitors of JNK, ERK, and p38 MAPKs. Inhibition of JNK and p38 MAPK significantly decreased activation of caspase- 3 mRNA in HepG2 in 


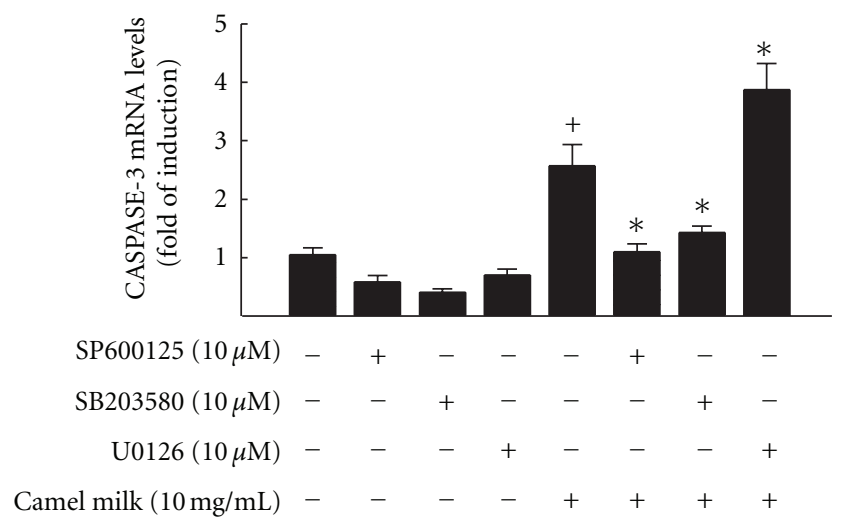

FIGURE 7: Effect of MAPKs inhibitors on camel milk mediated induction of caspase-3 mRNA levels in HepG2 cells. HepG2 cells were pretreated with for $2 \mathrm{~h}$ with JNK inhibitor, SP600125, p38 inhibitor, SB203580, and ERK inhibitor, U0126, before the addition of camel milk $(10 \mathrm{mg} / \mathrm{mL})$ for additional $6 \mathrm{~h}$. Thereafter, total RNA was isolated using TRIzol reagent and the mRNA levels of Caspase-3 were quantified using RT-PCR normalized to $\beta$-actin housekeeping gene as described Section 2. Duplicate reactions were performed for each experiment, and the values presented are the means \pm SEM $(n=6)$ of three independent experiments. ${ }^{+} P<0.05$ compared to untreated cells; ${ }^{*} P<0.05$ compared to camel milk-treated cells.

response to camel milk, whereas inhibition of ERK signaling pathway enhanced the camel milk-induced activation of caspase-3 mRNA. These finding support previous observations that ERK plays a role in cell survival [32] and confirm the proapoptotic effect of JNK [4].

Although the potential mediators in camel milk involved in apoptosis were not examined in this study, several previous studies have reported that camel milk contains considerably higher amounts of antioxidant vitamins, such as $\mathrm{E}$ and C, in comparison to bovine milk [33], lyzosomes [34], lactoferrins [34, 35], and immunoglobulines [35]. Among these mediators, lactoferrin, an iron-binding glycoprotein, is known to exert in vitro and in vivo antitumor activity [36]. In this context, it has been recently reported that lactoferrin inhibits the development of cancer through inhibiting CYP1A1 activation in 7,12-dimethylbenz[a] anthracene (DMBA-) induced hamster buccal pouch carcinoma model. Taken together, the results obtained from our laboratory and previously published reports, we speculate that lactoferrin could be responsible for camel milk-mediated effect.

In conclusion, to our knowledge, this will be the first study investigating the molecular mechanisms that govern the effect of camel milk on human cancer cells. This study clearly demonstrated that camel milk induces apoptosis in HepG2 and MCF7 cells through apoptotic- and oxidativestress-mediated mechanisms. These results are of potential clinical significance to humans in that it uncovers the molecular mechanism involved and could explain the anecdotal evidence for the successful use of camel milk in the treatment of various medical conditions.

\section{Conflict of Interests}

There is no conflict of interest.

\section{Acknowledgment}

The authors extend their appreciation to the Deanship of Scientific Research at King Saud University for funding the work through the research group project no. RGP-VPP-141.

\section{References}

[1] A. Vecchione and C. M. Croce, "Apoptomirs: small molecules have gained the license to kill," Endocrine-Related Cancer, vol. 17, no. 1, pp. F37-F50, 2010.

[2] W. P. Tsang, S. P. Y. Chau, S. K. Kong, K. P. Fung, and T. T. Kwok, "Reactive oxygen species mediate doxorubicin induced p53-independent apoptosis," Life Sciences, vol. 73, no. 16, pp. 2047-2058, 2003.

[3] S. W. Lowe and A. W. Lin, "Apoptosis in cancer," Carcinogenesis, vol. 21, no. 3, pp. 485-495, 2000.

[4] I. Herr and K. M. Debatin, "Cellular stress response and apoptosis in cancer therapy," Blood, vol. 98, no. 9, pp. 2603-2614, 2001.

[5] J. A. Hickman, "Apoptosis induced by anticancer drugs," Cancer and Metastasis Reviews, vol. 11, no. 2, pp. 121-139, 1992.

[6] N. Kontou, T. Psaltopoulou, D. Panagiotakos, M. A. Dimopoulos, and A. Linos, "The mediterranean diet in cancer prevention: a review," Journal of Medicinal Food, vol. 14, no. 10, pp. 1065-1078, 2011.

[7] M. S. Y. Haddadin, S. I. Gammoh, and R. K. Robinson, "Seasonal variations in the chemical composition of camel milk in Jordan," Journal of Dairy Research, vol. 75, no. 1, pp. 8-12, 2008.

[8] H. M. Korashy, M. A. El Gendy, A. A. Alhaider, and A. O. ElKadi, "Camel milk modulates the expression of aryl hydrocarbon receptor-regulated genes, Cyp1a1, Nqo1, and Gst1a2, in murine hepatoma hepa $1 \mathrm{clc} 7$ cells," Journal of Biomedicine and Biotechnology. In press.

[9] C. Conesa, L. Sánchez, C. Rota et al., "Isolation of lactoferrin from milk of different species: calorimetric and antimicrobial 
studies," Comparative Biochemistry and Physiology B, vol. 150, no. 1, pp. 131-139, 2008.

[10] E. I. el Agamy, R. Ruppanner, A. Ismail, C. P. Champagne, and R. Assaf, "Antibacterial and antiviral activity of camel milk protective proteins," Journal of Dairy Research, vol. 59, no. 2, pp. 169-175, 1992.

[11] E. R. M. Redwan and A. Tabll, "Camel lactoferrin markedly inhibits hepatitis C virus genotype 4 infection of human peripheral blood leukocytes," Journal of Immunoassay and Immunochemistry, vol. 28, no. 3, pp. 267-277, 2007.

[12] H. M. Korashy and A. O. S. El-Kadi, "The role of aryl hydrocarbon receptor and the reactive oxygen species in the modulation of glutathione transferase by heavy metals in murine hepatoma cell lines," Chemico-Biological Interactions, vol. 162, no. 3, pp. 237-248, 2006.

[13] R. H. Elbekai, H. M. Korashy, K. Wills, N. Gharavi, and A. O. S. El-Kadi, "Benzo[a]Pyrene, 3-methylcholanthrene and $\beta$-naphthoflavone induce oxidative stress in hepatoma hepa 1c1c7 cells by an AHR-dependent pathway," Free Radical Research, vol. 38, no. 11, pp. 1191-1200, 2004.

[14] B. N. M. Zordoky, M. E. Aboutabl, and A. O. S. El-Kadi, "Modulation of cytochrome P450 gene expression and arachidonic acid metabolism during isoproterenol-induced cardiac hypertrophy in rats," Drug Metabolism and Disposition, vol. 36, no. 11, pp. 2277-2286, 2008.

[15] K. J. Livak and T. D. Schmittgen, "Analysis of relative gene expression data using real-time quantitative PCR and the 2$\Delta \Delta$ CT method," Methods, vol. 25, no. 4, pp. 402-408, 2001.

[16] H. M. Korashy and A. O. S. El-Kadi, "The role of redoxsensitive transcription factors NF- $\kappa \mathrm{B}$ and AP-1 in the modulation of the Cyplal gene by mercury, lead, and copper," Free Radical Biology and Medicine, vol. 44, no. 5, pp. 795-806, 2008.

[17] N. A. Thornberry and Y. Lazebnik, "Caspases: enemies within,” Science, vol. 281, no. 5381, pp. 1312-1316, 1998.

[18] B. Zhivotovsky and G. Kroemer, "Apoptosis and genomic instability," Nature Reviews Molecular Cell Biology, vol. 5, no. 9, pp. 752-762, 2004.

[19] J. B. Johnston, A. F. Kabore, J. Strutinsky et al., "Role of the TRAIL/APO2-L death receptors in chlorambucil- and fludarabine-induced apoptosis in chronic lymphocytic leukemia," Oncogene, vol. 22, no. 51, pp. 8356-8369, 2003.

[20] Y. Matsui, Y. Tsuchida, and P. C. Keng, "Effects of p53 mutations on cellular sensitivity to ionizing radiation," American Journal of Clinical Oncology, vol. 24, no. 5, pp. 486-490, 2001.

[21] J. L. Watson, R. Hill, P. B. Yaffe et al., "Curcumin causes superoxide anion production and p53-independent apoptosis in human colon cancer cells," Cancer Letters, vol. 297, no. 1, pp. $1-8,2010$.

[22] N. Özören and W. S. El-Deiry, "Cell surface death receptor signaling in normal and cancer cells," Seminars in Cancer Biology, vol. 13, no. 2, pp. 135-147, 2003.

[23] A. Ashkenazi and V. M. Dixit, "Apoptosis control by death and decoy receptors," Current Opinion in Cell Biology, vol. 11, no. 2, pp. 255-260, 1999.

[24] T. Timmer, E. G. E. De Vries, and S. De Jong, "Fas receptormediated apoptosis: a clinical application?" Journal of Pathology, vol. 196, no. 2, pp. 125-134, 2002.

[25] S. B. Gibson, R. Oyer, A. C. Spalding, S. M. Anderson, and G. L. Johnson, "Increased expression of death receptors 4 and 5 synergizes the apoptosis response to combined treatment with etoposide and TRAIL," Molecular and Cellular Biology, vol. 20, no. 1, pp. 205-212, 2000.
[26] L. Ravagnan, T. Roumier, and G. Kroemer, "Mitochondria, the killer organelles and their weapons," Journal of Cellular Physiology, vol. 192, no. 2, pp. 131-137, 2002.

[27] G. Kroemer, "The proto-oncogene Bcl-2 and its role in regulating apoptosis," Nature Medicine, vol. 3, no. 6, pp. 614-620, 1997.

[28] D. M. Hockenbery, Z. N. Oltvai, X. M. Yin, C. L. Milliman, and S. J. Korsmeyer, "Bcl-2 functions in an antioxidant pathway to prevent apoptosis," Cell, vol. 75, no. 2, pp. 241-251, 1993.

[29] H. M. Korashy, A. Anwar-Mohamed, A. A. Soshilov, M. S. Denison, and A. O. S. El-Kadi, "The p38 MAPK inhibitor SB203580 induces cytochrome P450 1A1 gene expression in murine and human hepatoma cell lines through liganddependent aryl hydrocarbon receptor activation," Chemical Research in Toxicology, vol. 24, no. 9, pp. 1540-1548, 2011.

[30] J. Bian, K. Wang, X. Kong et al., "Caspase- and p38-MAPKdependent induction of apoptosis in A549 lung cancer cells by Newcastle disease virus," Archives of Virology, vol. 156, no. 8, pp. 1335-1344, 2011.

[31] K. Z. Guyton, D. R. Spitz, and N. J. Holbrook, "Expression of stress response genes GADD153, c-jun, and heme oxygenase1 in H2O2- and O2-resistant fibroblasts," Free Radical Biology and Medicine, vol. 20, no. 5, pp. 735-741, 1996.

[32] A. Bonni, A. Brunet, A. E. West, S. R. Datta, M. A. Takasu, and M. E. Greenberg, "Cell survival promoted by the RasMAPK signaling pathway by transcription-dependent and independent mechanisms," Science, vol. 286, no. 5443, pp. 1358-1362, 1999.

[33] Z. Farah, R. Rettenmaier, and D. Atkins, "Vitamin content of camel milk," International Journal for Vitamin and Nutrition Research, vol. 62, no. 1, pp. 30-33, 1992.

[34] E. I. el Agamy, R. Ruppanner, A. Ismail, C. P. Champagne, and R. Assaf, "Antibacterial and antiviral activity of camel milk protective proteins," Journal of Dairy Research, vol. 59, no. 2, pp. 169-175, 1992.

[35] G. Konuspayeva, B. Faye, G. Loiseau, and D. Levieux, "Lactoferrin and immunoglobulin contents in camel's milk (Camelus bactrianus, Campus dromedarius, and Hybrids) from Kazakhstan," Journal of Dairy Science, vol. 90, no. 1, pp. 38-46, 2007.

[36] A. Roseanu, P. E. Florian, M. Moisei, L. E. Sima, R. W. Evans, and M. Trif, "Liposomalization of lactoferrin enhanced its anti-tumoral effects on melanoma cells," BioMetals, vol. 23, no. 3, pp. 485-492, 2010. 

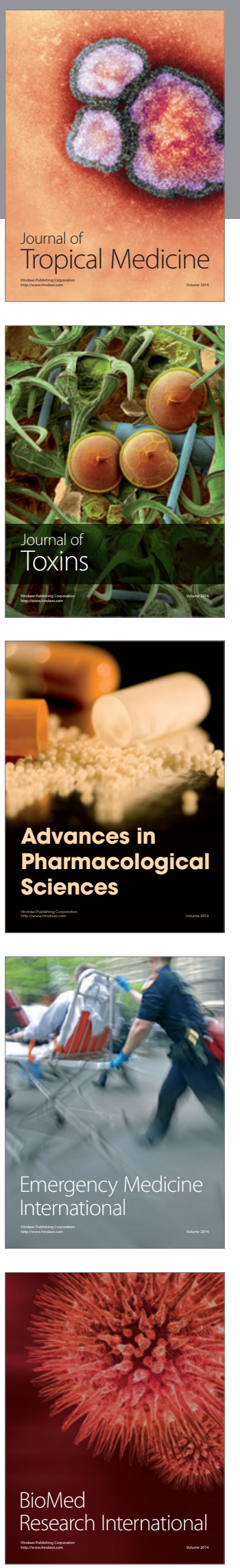
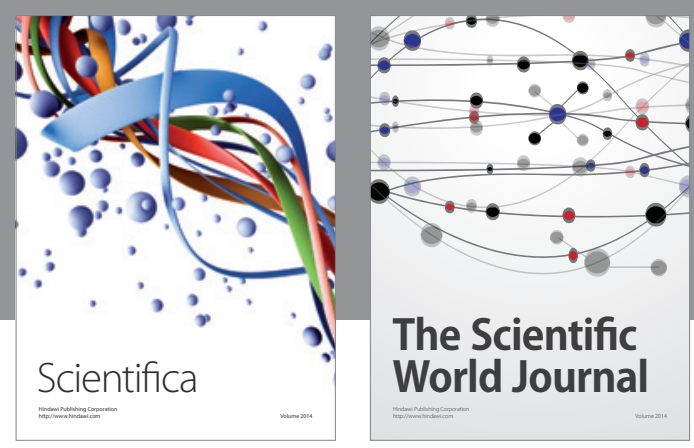

The Scientific World Journal
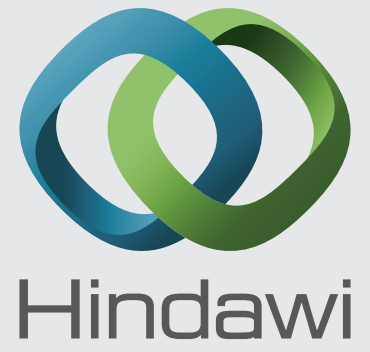

Submit your manuscripts at

http://www.hindawi.com
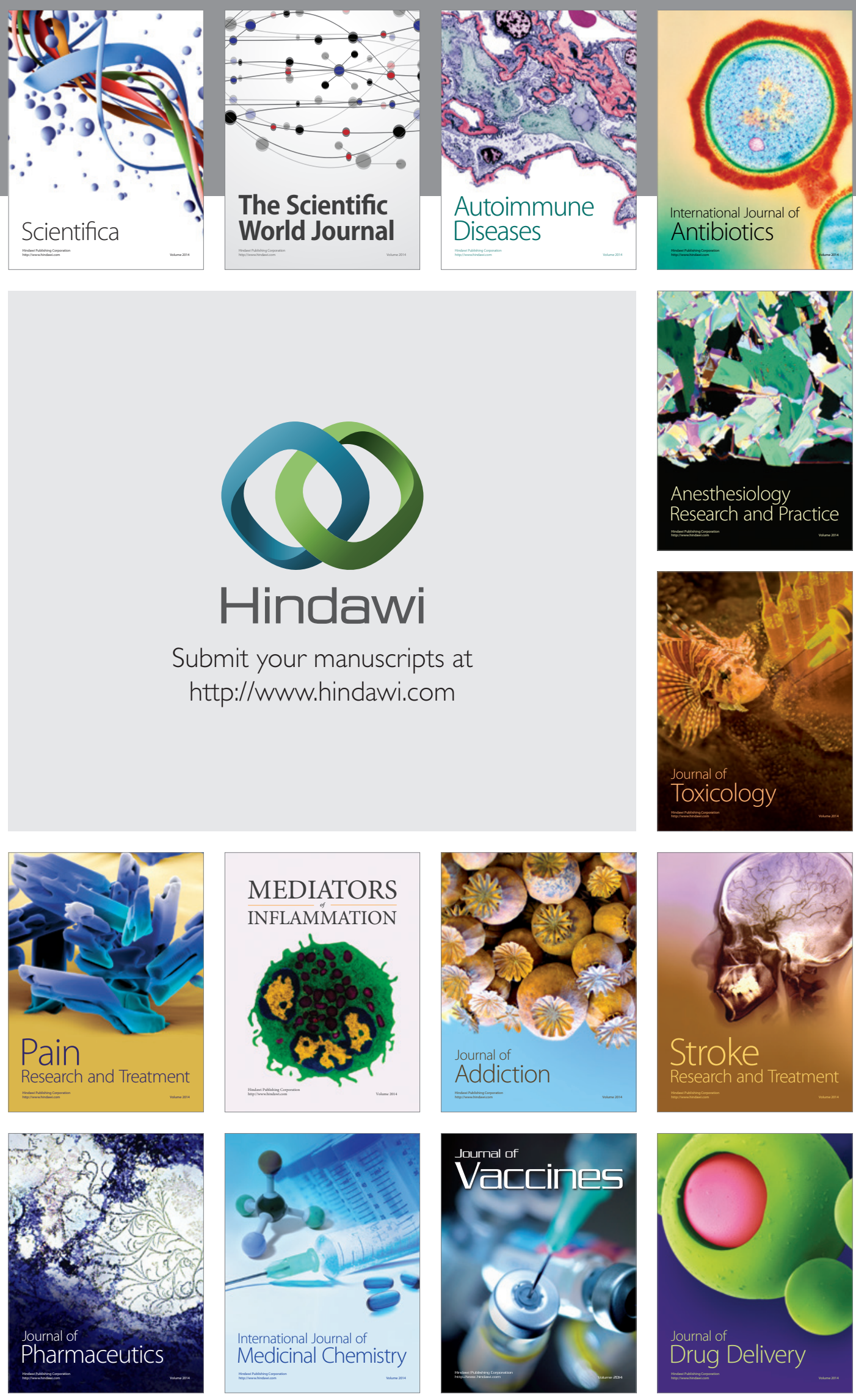